\title{
Big Data and Procedural Justice: Legitimizing Algorithms in the Criminal Justice System
}

\author{
Ric Simmons*
}

\section{INTRODUCTION}

Big data algorithms are becoming more common in the criminal justice system: they are used to provide more effective allocation of police resources, ${ }^{1}$ to notify police of potentially dangerous individuals at specific locations, ${ }^{2}$ to guide efforts to intervene with individuals before they engage in criminal activity, ${ }^{3}$ to advise judges making decisions about pre-trial detention, ${ }^{4}$ and to provide guidance to judges at sentencing. ${ }^{5}$ The debate about the propriety of using these algorithms has primarily focused on whether they are fair to the defendants they are evaluating. ${ }^{6}$ However, those in favor of using these tools in the criminal justice system must also consider another potential hurdle: whether these new tools will be accepted by the general public. For centuries, decisions in the criminal justice system have been made by individuals: police officers, judges, bureaucrats, and legislators. The general public is accustomed to these decision-makers and, for the

* Chief Justice Thomas J. Moyer Professor for the Administration of Justice and Rule of Law, Moritz College of Law, The Ohio State University. Thanks to Angela Lloyd and the participants in the 2017 Moritz College of Law Program on Data and Governance Round Table on Big Data and Criminal Law for helpful suggestions and edits. Also thanks to Kelsey Kornblut, Melissa Lenz, and Michael Willhelm for their research assistance.

1 See Maurice Chammah, Policing the Future, Verge (Feb. 3, 2016), http://www.theverge. com/2016/2/3/10895804/st-louis-police-hunchlab-predictive-policing-marshall-project [https://perma. cC/5CPM-2U42].

2 See Justin Jouvenal, The New Way Police Are Surveilling You: Calculating Your Threat 'Score,' WASH. Post (Jan. 10, 2016), https://www.washingtonpost.com/local/public-safety/the-newway-police-are-surveilling-you-calculating-your-threat-score/2016/01/10/e42bccac-8e15-11e5-baf4bdf37355da0c_story.html [https://perma.cc/AH53-ZYEL].

3 See Matt Stroud, The Minority Report: Chicago's New Police Computer Predicts Crimes, But Is It Racist?, VeRGE (Feb. 19, 2014, 9:31 AM), http://www.theverge.com/2014/2/19/5419854/the -minority-report-this-computer-predicts-crime-but-is-it-racist [https://perma.cc/Q5QN-BJ6G].

4 See Shaila Dewan, Judges Replacing Conjecture with Formula for Bail, N.Y. TIMES (June 26, 2015), https://www.nytimes.com/2015/06/27/us/turning-the-granting-of-bail-into-a-science.html [https://perma.cc/Y6LQ-3A77].

5 See Christopher Slobogin, Risk Assessment, in THE OXford HANDBOOK OF SENTENCING AND CoRrections 196, 203-05 (Joan Petersilia \& Kevin R. Reitz eds., 2012).

6 See Jason Tashea, Calculating Crime: Attorneys Are Challenging the Use of Algorithms to Help Determine Bail, Sentencing and Parole Decisions, 103 A.B.A. J. 54, 56, 59 (2017) (discussing the ongoing national debate about the use of algorithms in bail, sentencing, and parole decisions and how one of the chief ethical questions being grappled with is the trade-off between accuracy and fairness). 
most part, accepts their legitimacy. However, the public may not be as comfortable with the idea that critical criminal justice decisions are made or heavily influenced by computer programs instead of human beings. This question is a critical one for big data supporters: even if these tools can provide predictions that are more fair, efficient, and accurate than the clinical judgments made by human beings, they will never become widespread if they cannot gain public support.

\section{Big DATA’s PROCEDURAL JUSTICE CHALLENGE}

For years, psychologists have studied the perceived fairness of legal institutions using the principles of procedural justice. As its name implies, procedural justice focuses only on the procedural aspects of dispute resolution, not the substantive outcomes. More significantly, procedural justice is not concerned with "actual" fairness, but rather with people's perception of fairness: it is the study of what people believe to be fair procedures. ${ }^{7}$ The focus on procedure rather than substance flows naturally from the focus on perception rather than on reality. Numerous psychological studies have shown that whether or not an individual believes a particular interaction with authority is fair and legitimate depends primarily on whether or not the individual believed the procedure to be fair, not on the ultimate outcome of the interaction. ${ }^{8}$

Studies have repeatedly shown that perceived fairness encourages compliance with the law. People obey the law primarily because they believe that the system is legitimate; not because they fear sanctions if they transgress. ${ }^{9}$ In this way, "fair

7 See Paul G. Chevigny, Fairness and Participation, 64 N.Y.U. L. REv. 1211, 1211 (1989) (reviewing E. Allan Lind \& Tom R. Tyler, The Social Psychology of Procedural Justice (1988)).

8 See, e.g., Tom R. Tyler, Why PeOPle Obey the LAW 74 (1990) [hereinafter Tyler, Obey THE LAW]. Citing six separate psychological studies, Professor Tyler notes that:

Recent research confirms that people evaluate their experience in procedural terms. Such procedural effects have been found in trials as well as in other procedures used to resolve disputes, including plea bargaining, mediation, and decision making by police officers . .

. . Wherever procedural issues have been studied they have emerged as an important concern to those affected by the decisions.

Id. (citations omitted). There are two possible reasons for this popular focus on process rather than on substance. First, in a complex society, individuals receive a diverse variety of benefits (from monetary benefits to clean and safe streets) and pay a similarly diverse variety of costs (from paying taxes to having liberty restricted to a certain degree). Since it is impossible for any individual to keep track of all of the benefits received and all of the costs paid, the individual finds it easier to focus on the procedure itself and evaluate its fairness. If procedures are generally fair, the individual will conclude that in the long run he or she will pay and receive a just distribution of costs and benefits. The second possible explanation is that in a diverse society, individuals may disagree on what constitutes a just distribution of substantive benefits and costs, but can generally agree on what constitutes fair procedure. Id. at 109.

$9 \quad$ Id. at 61 . Professor Tyler interviewed over 1,500 people to determine why they obeyed a wide variety of criminal laws, and determined that belief in the legitimacy of the legal system was a significant influence in their decision not to break the law. Id. at 57-61. 
procedures can act as a cushion of support when authorities are delivering unfavorable outcomes. If unfavorable outcomes are delivered through procedures viewed as fair, the unfavorable outcomes do not harm the legitimacy of legal authorities."10 Thus, when evaluating a new process or procedure in the criminal justice system, such as the use of big data algorithms, it is important to consider whether they provide the public with a sense of procedural justice. A new criminal justice tool which is perceived to be unfair could contribute to the delegitimization and eventual destabilization of the criminal justice system. ${ }^{11}$ Therefore, when we evaluate two different procedural alternatives that could be used to accomplish a necessary task in the criminal justice system, such as setting bail based on the clinical judgment of a judge or based on the risk factors assessed by an algorithm, the amount of procedural justice provided by either alternative should be a relevant factor in deciding upon which process to rely. Similarly, if supporters of big data tools want to increase the prevalence of algorithmic decision making in the criminal justice system, they should seek to increase the procedural justice of these tools.

Studies in the field of procedural justice have found four overriding factors that determine whether or not an individual believes that a given procedure is fair $^{12}$ : (i) whether the decision-maker treats the individual with dignity and respect

A commonly cited example from the field of criminal justice is a study of men who dealt with police officers who had been called to their homes in response to accusations of domestic violence. The recidivism rate for these men for domestic violence was significantly lower if they felt that they were fairly treated by the police who initially responded to the call. The men's opinions about the quality of the procedural justice they received was a better predictor of their future law-abiding actions than whether they were arrested, fined, or taken down to the police station. Raymond Paternoster et al., Do Fair Procedures Matter? The Effect of Procedural Justice on Spouse Assault, 31 LAW \& SoC’y REV. 163, 163-204 (1997); see also Margaret B. Kwoka, Leaking and Legitimacy, 48 U.C. Davis L. REV. 1387, 1421-22 (2015) (summarizing studies that link the belief in the procedural justice of the laws to the likelihood of an individual breaking those laws in the context of immigration violations and tax fraud).

The perception of fairness is integral to any system of criminal justice, since a well-ordered society cannot be maintained based on the threat of sanction alone. As the criminal justice system is complex and involves innumerable institutions and procedures, it is critical to review all of them for the public's perception of legitimacy.

10 Tyler, OBEy the LAW, supra note 8, at 107. For example, studies have shown that defendants who plea bargained cases found the process to be a fairer procedure than resolving the criminal issues at trial, in part because the defendants had more control over the process of a plea bargaining procedure. See Tom R. Tyler, Citizen Discontent with Legal Procedures: A Social Science Perspective on Civil Procedure Reform, 45 AM. J. CoMP. L. 871 (1997) (showing a crisis of public confidence in the American justice system resulting from people's dissatisfying personal experiences with the court and the law).

11 There is always the danger that authorities will be able to provide a procedure that appears fair but in fact is not, thus creating a "false consciousness": an inaccurate sense of legitimacy on the part of the people that allows authorities to abuse their position and impose procedures, and distributive outcomes, which are "objectively" unfair. TYLER, OBEY THE LAW, supra note 8, at 111.

12 Tom R. Tyler, Social Justice: Outcome and Procedure, 35 InT’L J. Psychol. 117, 121 (2000) [hereinafter Tyler, Social Justice]; Tom R. Tyler \& Hulda Thorisdottir, A Psychological 
during his or her interaction with authorities; (ii) whether the decision-maker is perceived as neutral; (iii) whether the decision-maker is perceived as trustworthy; and (iv) whether the individual had the opportunity to participate in the procedure. ${ }^{13}$ The implications of procedural justice for criminal law in general have not been lost on commentators, ${ }^{14}$ but not much has yet been written about the specific impact that big data analytics may have on procedural justice issues. ${ }^{15}$

As noted below, big data algorithms do not appear to achieve a very high score on the procedural justice scale. Although these tools could potentially increase the perceived neutrality of the criminal justice system, they fare poorly in the areas of participation and trustworthiness.

\section{A. Interpersonal Respect}

The first factor is whether an individual who interacts with authorities is treated with dignity and respect by the decision-maker. ${ }^{16}$ This factor is unlikely to be particularly significant in evaluating the perceived legitimacy of big data algorithms, since the individuals who are subject to the algorithm's decisions will

Perspective on Compensation for Harm: Examining the September 11th Victim Compensation Fund, 53 DePaul L. ReV. 355, 380-82 (2003).

13 Tyler \& Thorisdottir, supra note 12, at 380-82.

14 See, e.g., Adam Lamparello, Incorporating the Procedural Justice Model into Federal Sentencing Jurisprudence in the Aftermath of United States v. Booker: Establishing United States Sentencing Courts, 4 N.Y.U. J.L. \& LIBERTY 112 (2009) (arguing for enhanced sentencing procedures in a special sentencing court to increase the level of procedural justice at sentencing); Michael M. O’Hear, Explaining Sentences, 36 FLA. ST. U. L. REV. 459, 469 (2009) (supporting a rule that requires judges to explain their reasoning at sentencing because it would enhance the procedural justice of the sentencing process); Jonathan D. Casper et al., Procedural Justice in Felony Cases, 22 LAw \& Soc’y REV. 483, 488, 498 (1988) (studying over 400 prisoners who were serving time in prison for felony convictions and concluding that procedural justice concerns were the strongest determinant of perceived fairness: amount of time their attorney spent with them, whether the police treated them with dignity, and how long they stayed in pre-trial detention); Kwoka, supra note 9, at 1419-26 (using procedural justice principles to prove that lack of transparency leads to a lack of perceived legitimacy in the United States government, which in turn leads to people defying the law and leaking classified information); Ric Simmons, Re-Examining the Grand Jury: Is There Room for Democracy in the Criminal Justice System?, 82 B.U. L. REv. 1, 55-64 (2002) (arguing that the grand jury should be preserved in part because of the procedural justice that it provides for the various players in the criminal justice system).

15 Procedural justice has been almost absent in the debates over big data algorithms in criminal justice. The arguments regarding big data algorithms in the criminal justice system have focused on whether these tools are substantively more accurate, more efficient, or more fair; for example, proponents of big data algorithms have focused on their increased efficiency and accuracy (see, e.g., Tashea, supra note 6, at 58), while opponents of these tools have argued that the underlying data may be tainted, and therefore big data algorithms will only reinforce pre-existing biases in the criminal justice system (see, e.g., Julia Angwin et al., Machine Bias, ProPublica (May 23, 2016), https://www.propublica.org/article/machine-bias-risk-assessments-in-criminal-sentencing [https://per ma.cc/GEP5-V37A]).

16 See Tyler, Social Justice, supra note 12, at 122. 
not be interacting directly with the software itself. Instead, the individuals will still be interacting with the human police officers, prosecutors, or judges who are acting on the software's recommendation. Still, the very use of computer algorithms to advise in these decisions may affect the dignity of those who are subject to these decisions: individuals may feel that their value as a human being is lessened when they are kept in on bail or given a longer sentence because a computer said it was the proper course of action. Humans may accept computers making decisions in some contexts, such as finding the cheapest airline flight or selecting a movie based on prior preferences, but when it comes to decisions of personal liberty, they may feel a loss of dignity when computers, and not people, are deciding their fate.

\section{B. Neutrality}

In the procedural justice context, neutrality refers to whether the decisionmaker follows rules impartially and is making objective, unbiased decisions based on facts. ${ }^{17}$ Big data algorithms hold great promise for increasing neutrality as well as the perceived neutrality of decision-makers: the software running the algorithm follows the same rules in the same way for every decision it makes.

However, one of the primary criticisms of big data algorithms is that they can reinforce existing biases and partialities that are already built into the system. If certain groups in society are more likely to be convicted because of their race or the neighborhood in which they live, then a sentencing algorithm that uses, as key factors, prior convictions or home address to determine the length of the sentence will exacerbate existing inequalities.

Of course, these critiques apply as much to individual human judgments as they do to an algorithm. It is arguably easier to remove race based criteria from a computer algorithm than from a decision made by an individual actor, since algorithms could theoretically be programmed to discount any factors which have been tainted by prior racial discrimination. For example, assume that a study has shown that in a certain jurisdiction black residents and white residents commit a certain type of crime with equal frequency, but because of inequities in the system, black residents are more likely to be convicted of the crime. ${ }^{18}$ Once this fact has been established, a sentencing algorithm can be programmed to remove the preexisting inequity by discounting the number of prior convictions of this crime by the appropriate amount for a black defendant, or by increasing the number of the prior convictions by the appropriate amount for a white defendant. Such adjustments could be made for all factors in which past racial bias has been

17 Id. This was first thought to be the most important aspect of a procedure in creating legitimacy, but studies have shown that it ranks behind process control and trustworthiness. See id.

18 There are certainly studies which show that police focus their attention and resources disproportionately on black communities, even when holding the crime rate constant, which would lead to the conclusion that more arrests would occur in predominantly black communities than in predominantly white communities. See, e.g., Katherine Beckett et al., Drug Use, Drug Possession Arrests, and the Question of Race: Lessons from Seattle, 52 Soc. ProBs. 419 (2005). 
documented, and they could be integrated into the decision-making process at every level, from determining probable cause to setting bail to determining an appropriate sentence. Even if we could trust every human judge to be aware of these examples of pre-existing racial bias, and even if we could be confident that each judge would be sympathetic to the need to adjust decisions appropriately, it would be impossible for any human judge to take into account all of these potential discounts with the appropriate level of precision. Only computer algorithms could hope to do this effectively.

\section{Trustworthiness}

In the field of procedural justice, trustworthiness can be established in two ways: first, if the participant feels a personal connection to the decision-maker (for example, the participant perceives that the decision-maker comes from the same group as the participant); and second, if the decision-maker explains his or her decisions. ${ }^{19}$ Big data algorithms will never achieve trustworthiness through a personal connection; most defendants will not feel any kinship to a computer program designed by an anonymous corporation. ${ }^{20}$ Thus, an algorithm will only appear trustworthy if its calculations are transparent and comprehensible to the person being affected.

Unfortunately, big data algorithms are notoriously opaque and incomprehensible, sometimes even to those who are applying them. Many others have commented on the need for transparency when applying big data algorithms, primarily in order to ensure that the factors used by the algorithms are not proxies for unconstitutional factors such as race. ${ }^{21}$

19 See, e.g., Tom R. Tyler \& E. Allan Lind, A Relational Model of Authority in Groups, in 25 AdVANCES IN EXPERIMENTAL Social Psychology 115, 151-91 (Mark P. Zanna ed., 1992) (explaining the preconditions for the effective functioning of authorities).

20 Of course, the level of kinship that defendants feel with a judge under a traditional system will vary greatly. A defendant is unlikely to feel a connection with a judge who comes from a different economic class, has a different level of education, or is of a different ethnicity. See, e.g., Multiracial in America: Proud, Diverse and Growing in Numbers, Pew ReseArCh Ctr. (June 11, 2015), www.pewsocialtrends.org/2015/06/11/multiracial-in-america/ [https://perma.cc/4AVM-EQ

JN] (finding that relatively few adults say they have a lot in common with those who do not share their own racial background); Sandra Susan Smith, Race and Trust, 36 AnN. Rev. Soc. 453, 456 (2010), http://sociology.berkeley.edu/sites/default/files/faculty/Smith/RACE\%20AND\%20TRUST .pdf [https://perma.cc/C9EP-FLCD] (discussing how members of minority racial groups report substantially more misanthropy (less trust) than members of the majority); Alberto Alesina \& Eliana La Ferrara, Who Trusts Others?, 85 J. PUB. ECON. 207 (2002) (finding that factors associated with low trust include belonging to a group that historically felt discriminated against, being economically unsuccessful in terms of income and education, and living in a racial mixed community or in one with a high degree of income disparity).

21 See Elizabeth E. Joh, The New Surveillance Discretion: Automated Suspicion, Big Data, and Policing, 10 Harv. L. \& Pol'y ReV. 15, 40 (2016) (discussing the need for transparency and accountability measures to address concerns raised by expanded surveillance discretion); Laurel Eckhouse, Opinion, Big Data May Be Reinforcing Racial Bias in the Criminal Justice System, WASH. 
Opacity in sentencing is not a problem unique to big data. Other commentators have noted the procedural justice benefits to having the trial judge fully justify her sentencing decision; ${ }^{22}$ this need becomes even greater if the judge's reasoning cannot be derived implicitly from the facts but rather are the result of an algorithm that takes dozens or perhaps hundreds of seemingly irrelevant factors under consideration. As of now, the courts have generally refused to impose a duty on trial court judges to explain sentencing decisions. ${ }^{23}$ Proponents of big data algorithms may want to impose a transparency requirement in order to increase the trustworthiness of their system.

\section{Participation in the Process}

Individuals are more likely to believe that a procedure is legitimate if they can participate in the process and express their views to the decision-maker. For example, an individual will be more likely to see a process as fair if she is able to tell her story directly to the decision-maker. ${ }^{24}$ This is generally termed "process control," though the name is somewhat misleading, since studies have shown that individuals value this ability to participate even if their participation has no ability to affect the outcome of the procedure. ${ }^{25}$

In general, the legal system and particularly the criminal justice system fares poorly in the category of process control, since a defendant is represented by counsel during all formal procedures and thus rarely gets a chance to speak to the decision-maker himself. ${ }^{26}$ But big data algorithms are almost certain to exacerbate

Post (Feb. 10, 2017), https://www.washingtonpost.com/opinions/big-data-may-be-reinforcing-racialbias-in-the-criminal-justice-system/2017/02/10/d63de518-ee3a-11e6-9973-c5efb7ccfb0d_story.html ?utm_term=.dcda87fcce40 [https://perma.cc/4KFS-MHR9] (urging for more transparency of risk assessment tools to determine whether they have disparate impacts on defendants of different races); David Robinson et Al., Civil Rights, Big Data, and Our Algorithmic Future 20 (2014) (discussing how transparency in police surveillance technologies is vital to mitigate discriminatory police practices); Exec. Office of the President, Big DAta: A Report on Algorithmic Systems, OPPORTUNITY, AND CIVIL RIgHTS 21 (2016) (discussing how transparency and accountability on data input and processes can help ensure that data and algorithmic systems are not used in ways that exacerbate unwarranted disparities in the criminal justice system).

22 See Lamparello, supra note 14, at 136.

23 See, e.g., United States v. Cunningham, 429 F.3d 673, 675 (7th Cir. 2005).

24 See Tom R. Tyler et al., Influence of Voice on Satisfaction with Leaders: Exploring the Meaning of Process Control, 48 J. Personality \& Soc. Psychol. 72 (1985).

25 See, e.g., E. Allan Lind et al., Voice, Control, and Procedural Justice: Instrumental and Noninstrumental Concerns in Fairness Judgments, 59 J. PERSONALITY \& SoC. Psychol. 952 (1990). One study found that allowing victims to testify at sentencing hearings increased the victim's perception of the fairness of the process even if their arguments had no effect on the ultimate sentence given to the defendant. See Anne M. Heinz \& Wayne A. Kerstetter, Pretrial Settlement Conference: Evaluation of a Reform in Plea Bargaining, 13 LAW \& Soc’y REV. 349 (1979).

26 See, e.g., Alexandra Natapoff, Speechless: The Silencing of Criminal Defendants, 80 N.Y.U. L. REV. 1449, 1458 (2005) (explaining how represented criminal defendants rarely speak since they are encouraged to be quiet and to let their lawyers do the talking). 
this problem. One of the few times that a defendant gets a chance to speak directly to a decision-maker is at sentencing, when he can address the judge in support of his plea for a lighter sentence. ${ }^{27}$ In the traditional model, the defendant may gain a sense of process control by speaking to the judge, even if the defendant has been warned that the judge is unlikely to change the ultimate sentence in response to his arguments. If, in contrast, the defendant knows that the ultimate decision has effectively already been made by a computer program, he will know that he is in fact not speaking to the true decision-maker-indeed, that the decision has already been made even before the sentencing hearing begins. This will be the exact opposite of process control: the defendant will have no chance for real participation in the process and no opportunity to present his case to the true decision-maker in the case.

\section{THE WAY FORWARD}

Proponents of using big data tools in the criminal justice system need to pay attention to the procedural justice aspects of these tools, since they will face consistent opposition from the public unless their algorithms are perceived to be fair and legitimate. Unfortunately, some factors in achieving a high level of procedural justice are inherently incompatible with big data algorithms: defendants will never feel a personal connection with the decision-maker, which will impede their trustworthiness, and they will feel even less process control as computers become a stronger influence on the decisions that are made. But there are some improvements which could be made to increase the procedural justice of these tools. First, the algorithms could be more transparent in order to increase trustworthiness; and second, the algorithms could be designed to remove preexisting biases in the original data in order to increase their neutrality. Happily, these two improvements would improve the substance of the algorithm's predictions as well. Transparency would help to ensure that the algorithms are in fact comporting with constitutional requirements, ${ }^{28}$ and using data that has been

27 See id. at 1464-65 (discussing how defendants are entitled to address the court at sentencing and how sentencing is the hearing at which the court is most likely to hear the defendant speak); see also FED. R. CRIM. P. 32(i)(4)(A)(ii) (mandating that the court allow the defendant to speak or present any information to mitigate the sentence before imposing the sentence).

28 See supra note 21 and accompanying text. There are already calls for greater transparency in these algorithms. See Criminal Law-Sentencing Guidelines-Wisconsin Supreme Court Requires Warning Before Use of Algorithmic Risk Assessments in Sentencing-State v. Loomis, 881 N.W.2d 749 (Wis. 2016), 130 HARV. L. REV. 1530, 1537 (2017) (advocating for restrictions on the use of big data tools in sentencing, such as "excluding risk assessments that keep their methodology secret or reining in their use until more studies are available"). However, courts have not yet imposed any such requirement. State v. Loomis, 881 N.W.2d 749 (Wis. 2016). In Loomis, the defendant was sentenced using a COMPAS risk assessment tool and argued that the use of COMPAS violated his due process rights, arguing that the secrecy of the algorithm violated his right to an individualized sentence, a right to be sentenced on accurate information, and a right not to have his gender be a consideration in sentencing. Id. at 757. The Wisconsin Supreme Court ultimately affirmed the denial 
"scrubbed" clean of any pre-existing bias would make the ultimate predictions more fair and more accurate. ${ }^{29}$

of the defendant's motion, but it did issue warnings that trial courts should proceed with caution when weighing risk assessments. Id. at 770-72.

Private companies such as Northpointe (which owns the COMPAS algorithm) and PredPol have refused to make their algorithms public, since this is valuable proprietary information. See Mitch Smith, In Wisconsin, a Backlash Against Using Data to Foretell Defendants' Futures, N.Y. Times (June 22, 2016), https://www.nytimes.com/2016/06/23/us/backlash-in-wisconsin-againstusing-data-to-foretell-defendants-futures.html?mcubz=3 [https://perma.cc/RFW4-A5H9] (noting how the general manager of the company that created COMPAS stated: "The key to our product is the algorithms, and they're proprietary .... . We've created them, and we don't release them because it's certainly a core piece of our business.”). The Arnold Foundation, in contrast, has released the details of its PSA tool, which is used for pre-trial detention determinations. Tashea, supra note 6, at 58. A representative of the Arnold Foundation argued that "it's important from a fairness perspective for all the parties to understand what goes into a risk assessment.” Id. at 60.

29 See Devlin Barrett, Holder Cautions on Risk of Bias in Big Data Use in Criminal Justice, WALL ST. J. (Aug. 1, 2014, 2:10 PM), https://www.wsj.com/articles/u-s-attorney-general-cautions-on -risk-of-bias-in-big-data-use-in-criminal-justice-1406916606 [https://perma.cc/5R48-F32C] (Former Attorney General Eric Holder warned that data-driven criminal justice programs that are based on factors such as education level, socioeconomic background, or neighborhood could exacerbate unwarranted and unjust disparities in the criminal justice system); Cathy O'Neil, Justice in the Age of Big Data, TED (Apr. 6, 2017), http://ideas.ted.com/justice-in-the-age-of-big-data/ [https://perma. cc/7S9Q-TF8X] (discussing how predictive policing software has bias programmed into it); Eckhouse, supra note 21 (discussing how data-driven decision-making risks exacerbating, rather than eliminating, racial bias in criminal justice); Kevin Miller, Total Surveillance, Big Data, and Predictive Crime Technology: Privacy's Perfect Storm, 19 J. TeCH. L. \& PoL’y 105, 123-25 (2014) (discussing how predictive systems have biases built into them). 